\title{
AC and DC global electric circuit properties and the height profile of atmospheric conductivity
}

\author{
Irina G. Kudintseva ${ }^{1}$, Alexander P. Nickolaenko ${ }^{2,}{ }^{\star}$, Michael J. Rycroft ${ }^{3,4}$, Anna Odzimek ${ }^{5}$ \\ ${ }^{1}$ V.N. Karazin Kharkov State University, Kharkov, Ukraine \\ ${ }^{2}$ A.Ya. Usikov Institute for Radio-Physics and Electronics, National Academy of Sciences of the Ukraine, Kharkov, Ukraine \\ ${ }^{3}$ CAESAR Consultancy, Cambridge, United Kingdom \\ ${ }^{4}$ University of Bath, Department of Electronic and Electrical Engineering, Bath, United Kingdom \\ ${ }^{5}$ Institute of Geophysics, Polish Academy of Sciences, Warsaw, Poland
}

\author{
Article history \\ Received September 15, 2015; accepted September 1, 2016. \\ Subject classification: \\ Vertical conductivity profile of atmosphere, Global electric circuit, ELF radio wave propagation, Schumann resonances, \\ Characteristic heights, D-region ionosphere, Effects of aerosols, Fair weather field.
}

\begin{abstract}
An apparent discrepancy is pointed out - at all heights, and by up to an order of magnitude - between the height profiles of atmospheric conductivity derived at AC using ELF propagation studies, especially from information on Schumann resonance of the Earth-ionosphere cavity, and using a model of the DC global atmospheric electric circuit. This serious issue is resolved by creating a hybrid profile of these two mid-latitude profiles, the first of which refers to conditions by day and the second by night. This hybrid profile is thus a first order attempt to represent globally averaged conditions. Close to the Earth's surface, where the resistance of the atmosphere is largest, the properties of the DC global model exert the greatest influence, whereas in the middle atmosphere, at heights between 40 and $100 \mathrm{~km}$, full wave computations show that the AC results are the more crucial. The globally averaged hybrid profile presented here has some limitations, and the physical reasons for these are addressed. They are due to the presence of aerosol particles of ice and/ or of meteoric material which reduce the ionospheric D-region conductivity by an order of magnitude over only $\sim 2 \mathrm{~km}$ of height, thereby causing ledges of ionisation. In the context of the globally averaged profile, published observations of the ionospheric effects of the giant gamma-ray flare from SGR 1806-20 (a neutron star having an enormously large magnetic field) occurring at 21:30 U.T. on December 27, 2004, are briefly discussed.
\end{abstract}

\section{Introduction}

The atmospheric electrical conductivity is defined as $\sigma=e\left(\mu_{+} n_{+}+\mu_{-} n_{-}\right)$, where $e$ is the magnitude of the charge on the electron, $\mu_{+}$and $\mu_{-}$are, respectively, the mean positive and negative ion mobilities (where the ion mobility is the stationary velocity acquired by an ion in a unit electric field) and $n_{+}$and $n_{-}$are the concentrations of small positive and negative ions present in the atmosphere [Rycroft et al. 2008]. The conductivity thus depends mainly on the positive and negative ion densities.

Knowledge of the vertical profile of the atmospheric electrical conductivity is important when solving many problems in geophysics. For example, the conductivity within the boundary layer essentially determines the strength of the fair weather electric field at the Earth's surface. The conductivity of the air controls the leakage current in the global Earth-ionosphere electric circuit. The conductivity at $70-90 \mathrm{~km}$ altitude determines the crucial properties of the Earthionosphere waveguide, namely the phase velocity and the attenuation rate of radio waves from VLF transmitters. At lower frequencies, natural electromagnetic oscillations of the Earth-ionosphere cavity, termed Schumann resonances, were predicted theoretically by Schumann [1952]. They have been observed at frequencies between a few $\mathrm{Hz}$ and several tens of $\mathrm{Hz}$ and they have been interpreted to give conductivity information; see, e.g., Balser and Wagner [1960], Chapman and Jones [1964], Galejs [1965], Rycroft [1965], Jones [1976], Sao et al. [1973], Bliokh et al. [1977], Tran and Polk [1979a,b], Polk [1983], Sentman [1990, 1995, 1996], Fullekrug [2000, 2005], Fullekrug et al. [2002], Nickolaenko and Hayakawa [2002, 2014], Kulak et al. [2003], Rakov and Uman [2003, Section 13.4], Sato and Fukunishi [2003], Roldugin et al. [2004], Williams et al. [2006], Sátori et al. [2013] and Dyrda et al. [2015] and references therein. For their interpretation, the air conductivity has to be considered across the entire range 
of altitudes from 0 to $100 \mathrm{~km}$. Having a realistic conductivity profile is mandatory for successful modelling of the Schumann resonances using modern direct techniques of computation such as the finite difference time domain (FDTD) method; see, e.g., Simpson and Taflove [2002], Otsuyama et al. [2003], Soriano et al. [2005], Yang and Pasko [2005], Yang et al. [2006], Simpson [2009], and Zhou and Qiao [2015].

Unfortunately, experimental data on middle atmosphere conductivity are rather scarce. One of the reasons for this is that for radio physical remote sensing methods in the ELF frequency range $(f<3 \mathrm{kHz})$ there are no man-made sources available. Direct measurements made from aircraft can only be undertaken at up to about $15 \mathrm{~km}$ altitude or from balloons up to about 35 km [e.g., Holzworth 1991, Curto et al. 2001]. Only geophysical rockets are able to provide information on the conductivity in the altitude range from $35-100 \mathrm{~km}$, but such launches are relatively rare and very expensive. Thus, the observational base of directly measured conductivity profiles is rather limited.

Much information on the electron and ion concentrations in the lower ionosphere is obtained by different methods including various probes aboard sounding rockets, and radio wave propagation experiments to receivers aboard rockets (see, e.g., Hale et al. [1981], Hale [1984], Friedrich and Torkar [2001]) and also different ground-based radar systems. Hale [1984] shows a sharp electron density ledge at the bottom of the D-layer. Using such data sets, Mechtly et al. [1972], Park and Dejnakarintra [1973], Widdel et al. [1976], Swider [1988] and Croskey et al. [1990] published models of the height profile of conductivity. A fairly recent and very valuable review by Friedrich and Rapp [2009] presented rocket observations, which typically show sharp gradients of electron density (termed "ledges") and also a variation of electron density at any particular height above $70 \mathrm{~km}$ by up to \pm one order of magnitude, particularly at auroral latitudes.

Friedrich and Rapp [2009] considered the importance of nanometer-sized particles as aerosols in the lower ionosphere. Electrons are captured by these aerosols, causing a marked reduction of the electron density and hence of the electrical conductivity. Aerosol ions are heavier than atmospheric molecular ions and this effect also contributes to reducing the conductivity. Tiny ice crystals (especially at high latitudes during summer) and ablated meteoric material [Plane 2003] form these aerosols. McNeil et al. [1998] showed that the bottoms of the sodium, calcium and magnesium ion layers were found at altitudes between 83 and $90 \mathrm{~km}$. Williams et al. [2015] have emphasized the role played by meteoric ions in forming a sharp ledge in the conductivity at $\sim 85 \mathrm{~km}$ altitude. Their calculations show that "the conduction current and the displacement current are matched at the height of the observed ledge over a wide range of VLF frequencies, pinning this altitude as the sharp boundary for the global VLF waveguide".

Friedrich et al. [2013] presented high latitude rocket observations obtained by several techniques simultaneously which show a very sharp ledge at night at $80 \mathrm{~km}$ on one night and at $79 \mathrm{~km}$ on two other occasions. The electron density (and hence also the conductivity) increases by two orders of magnitude from 80 to $90 \mathrm{~km}$ altitude. Schlegel and Fullekrug [2002] evaluated the conductivity profile, $\sigma(h)$, from 70 to $100 \mathrm{~km}$ using EISCAT measurements at high latitude. They showed that the conductivity was between $3.10^{-5}$ and $3.10^{-4} \mathrm{~S} / \mathrm{m}$ at $84 \mathrm{~km}$, and with the scale height for the variation of $\log _{10} \sigma$ with altitude lying between 6 and $8 \mathrm{~km}$. In their Figure 2d, Kero et al. [2014] have compared EISCAT (high latitude) observations made at altitudes down to $60 \mathrm{~km}$ with results derived from their new spectral riometer technique.

Han et al. [2011] have interpreted observed daytime mid-latitude VLF sferics produced by lightning discharges to find the electron density profile from 50 to $90 \mathrm{~km}$, with the electron density typically increasing from $10^{7}$ to $10^{10} \mathrm{~m}^{-3}$. They compared this with values derived from other observations of VLF transmitter signals, from the ionospheric reference ionosphere (IRI) model and from the FIRI model of Friedrich and Torkar [2001]. A general, rather than near perfect, agreement was found. Sferics observed at night, known as tweeks, exhibit a fundamental cut-off frequency near $1.8 \mathrm{kHz}$ and higher harmonics (see Han et al. [2011], and references therein). These are interpreted by Tan et al. [2015] to show that at low latitudes the average electron density increases from $3 \cdot 10^{7} \mathrm{~m}^{-3}$ at $82 \mathrm{~km}$ to $2 \cdot 10^{8} \mathrm{~m}^{-3}$ at 87 $\mathrm{km}$, i.e. by nearly an order of magnitude over a height range of $5 \mathrm{~km}$. Their electron density values were slightly less than those given by the IRI-2012 model. However, these observations do not show a sharp ledge in the electron density.

The relative lack of observations is compensated in part by modern numerical simulations. Equations for the ionisation balance are used for the multi-component plasma in the framework of a more or less realistic model of the density and composition of the atmosphere, and accounting for the ionising electromagnetic radiation. For example, Pavlov [2014, 2016] has investigated the photochemistry of the ionospheric D-region in detail. In such a way the altitude profiles for the concentration of the conducting particles (heavy ions from several different sources, ion complexes and various aerosols and dust particles) and free electrons 
may be calculated and the resulting conductivity of the medium may be determined. The system of balance equations comprises up to 200 equations, which are solved by modern computers using the Monte Carlo method, e.g., Inan et al. [2007]. It is found that the conductivity $\sigma(h)$ increases rapidly at altitudes above about $55 \mathrm{~km}$, where the concentration of electrons exceeds the negative ion density. Therefore, the $\sigma(h)$ profile bends sharply at around $55 \mathrm{~km}$; it exhibits a "knee" at this altitude.

The objective of the present paper is simply to demonstrate the applicability of Schumann resonance phenomena as a probe for testing the conductivity profiles found by other techniques, including for models of the DC global circuit, many important contributions to which have been discussed by Wilson [1929], Roble and Tzur [1986], Williams [2003, 2009], Markson [2007], Rycroft et al. [2008, 2012], Rycroft and Harrison [2012], and Williams and Mareev [2014]. For these demonstrations we shall use the particular profiles suggested by Cole and Pierce [1965], which is a model daytime profile, and by Rycroft et al. [2007], a model night-time profile designed to apply to conditions when sprites are observed (see also Huang et al. [1999], and Fullekrug et al. [2006]). It is noteworthy, but not at all surprising, that the values of conductivity in the first model exceed these of the second one at all heights by about an order of magnitude.

\section{Conductivity profiles using DC and AC global cir- cuit data}

In models of the DC global atmospheric electric circuit (see, e.g., Rycroft et al. [2000]), various different empirical or semi-empirical height profiles of the conductivity of the air have been used; see, for example, Hays and Roble [1979], Roble and Hays [1979], Makino and Ogawa [1984, 1985], Ogawa [1985], Roble and Tzur [1986], Sapkota and Varshneya [1990], Tinsley and Zhou [2006], Rycroft et al. [2007, 2008], Tinsley [2008], Rycroft and Odzimek [2010], Odzimek et al. [2010], Rycroft and Harrison [2012] and Rycroft et al. [2012]. In all such models the conductivity of the air is considered to be produced near the Earth's surface by radioactive elements escaping from the surface and, higher up, by galactic cosmic rays colliding with air molecules [Harrison et al. 2014]. In some models, spatial variations due to orography and temporal variations due to changing solar/geomagnetic activity and to volcanic aerosols are included. Electrons become detached and then rapidly attach themselves to molecules of air to form relatively heavy negative ions. The peak ion production rate occurs at heights near $15 \mathrm{~km}$ [Harrison et al. 2014]. Thus the conductivity of the air rises rapidly from values $\sim 10^{-14}$
$\mathrm{S} / \mathrm{m}$ just above the surface of the Earth to values about a thousand times greater at $30 \mathrm{~km}$ altitude, in the stratosphere. The conductivity continues to increase, reaching values exceeding $10^{-7} \mathrm{~S} / \mathrm{m}$ in the lowest ionosphere.

Figure 1 depicts the average conductivity profiles of the atmosphere considered in this work. The original smooth red line is the night-time profile used for DC global electric circuit studies [Rycroft et al. 2007]. For the DC circuit, the most crucial region is below 15 $\mathrm{km}$ altitude; as shown by Rycroft et al. [2008], more than $95 \%$ of the resistance of the global circuit lies here. This profile was defined up to $80 \mathrm{~km}$ altitude, and we have extended it above $75 \mathrm{~km}$ with an exponential function having a scale height of $2.57 \mathrm{~km}$. It may be noted that in this night-time model the conductivity increases by two orders of magnitude from $80 \mathrm{~km}$ up to $91 \mathrm{~km}$, but there is no $2 \mathrm{~km}$ thin ledge.

The black line with dots shows the classical profile introduced by Cole and Pierce [1965]. This daytime profile was derived by considering theoretically the production and loss (but not transport) of ionisation throughout the atmosphere due to radioactivity from the ground, cosmic rays and solar radiation. Ions heavier than normal atmospheric ions were, however, not considered; thus, their conductivity value at a particular height may be an overestimate. Ionic conductivity dominates below $50 \mathrm{~km}$ and electron conductivity above $60 \mathrm{~km}$. The knee in this profile near $55 \mathrm{~km}$ altitude is crucial for the AC circuit properties owing to the fact that the so-called "electric" characteristic height is found here. This is the height where the conduction current density and the displacement current density become equal at the fundamental Schumann resonance frequency of $8 \mathrm{~Hz}$. Physically, this is the height above which the electric field of this Schumann resonance starts to decrease rapidly with altitude [Greifinger and Greifinger 1978, Nickolaenko and Rabinowicz 1982, Kirillov 1993, Sentman 1995, Kirillov 1996, Sentman

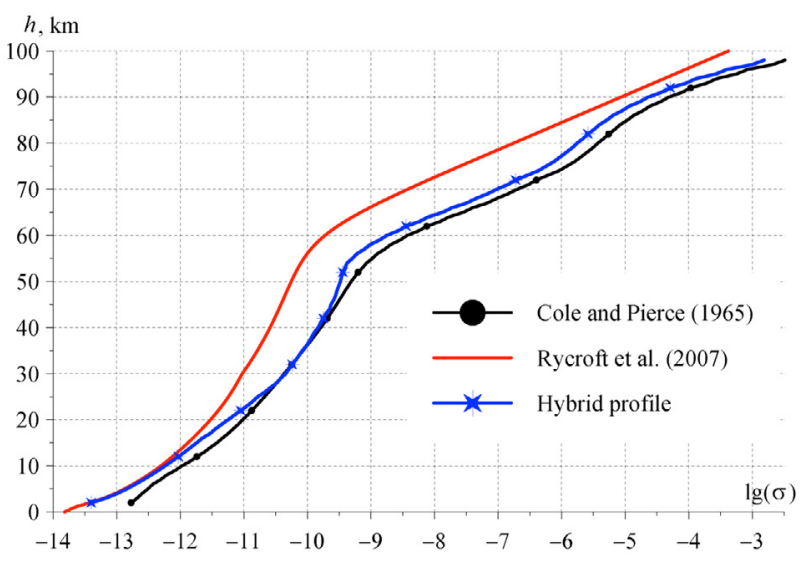

Figure 1. Comparison of height profiles of air conductivity $\sigma$, given in units of $S / m$. 
1996, Fullekrug 2000, Mushtak and Williams 2002, Pechony and Price 2004, Williams et al. 2006, Greifinger et al. 2007, Pechony 2007, Galuk et al. 2015]. The other important characteristic ("magnetic") height is $\sim 95 \mathrm{~km}$ : the wave magnetic field penetrates to this altitude. Unfortunately, the Cole and Pierce [1965] profile does not match either the DC or AC observational data. The function $\sigma(h)$ must be transformed to somewhat lower values in the troposphere and to higher conductivities above $40 \mathrm{~km}$ altitude, thus forming the hybrid day/night profile, which is thus a global profile, averaging over all local times (blue line with stars in Figure 1). This modification allows us to fit the Schumann resonance data well [Nickolaenko et al. 2016].

The hybrid profile is coincident with the DC red profile in the troposphere and it matches the classical Cole and Pierce [1965] height dependence around 25 $30 \mathrm{~km}$ altitude, remaining rather close to this profile above $40 \mathrm{~km}$. As we shall see below, deviations from this classical profile lead to realistic values of the ELF radio propagation constant and to reasonable Schumann resonance patterns.

The values relevant to this global hybrid profile are listed in Table 1 in the Appendix. The table contains the altitude above the ground, the relevant conductivity of the air column of $1 \mathrm{~m}^{2}$ cross-section, and the logarithm of air conductivity, in units of $S / m$.

\section{Full wave solution of the Schumann resonance problem and standard ELF propagation constant}

A realistic model of the Earth-ionosphere cavity incorporates the perfectly conducting spherical Earth surrounded by a poorly conducting air shell bounded by the horizontally stratified ionospheric plasma. The relative dielectric constant of the medium above the ground is given by $\varepsilon(r)=1+i \frac{\sigma(r)}{\omega \varepsilon_{0}}$, where $r$ is the radius vector in a spherical coordinate system $(r, \theta, \varphi)$ with the origin at the Earth's centre. The electromagnetic problem in an isotropic inhomogeneous resonator is solved via the following steps (see, e.g., Bliokh et al. [1980], Nickolaenko and Hayakawa [2002]). After writing Maxwell's equations for the electric and magnetic field components and introducing scalar (or Debye) potentials, we choose the potential and the Helmholtz equation corresponding to the transverse magnetic wave (E-wave), as only this wave propagates at ELF. The Earth-ionosphere cavity is taken to be uniform in the angular coordinates $\theta$ and $\varphi$, while its electric properties vary along the radius; the relative permittivity of the atmosphere is $\varepsilon=\varepsilon(r, \omega)$. This allows us to separate variables in the usual way, to obtain the standard tesseral functions, and to arrive at the following equation for the radial function [Bliokh et al. 1980]:

$$
\begin{aligned}
& \left\{\frac{d^{2}}{d r^{2}}+k^{2} \varepsilon(r)-\frac{n(n+1)}{r^{2}}-\right. \\
& \sqrt{\left.\varepsilon(r) \frac{d^{2}}{d r^{2}}\left[\frac{1}{\sqrt{\varepsilon(r)}}\right]\right\} r R(r)=0}
\end{aligned}
$$

The solutions to Equation (1) are expressed as the spherical Hankel functions $h_{n}^{(1)}(k r \sqrt{ } \varepsilon)$ and $h_{n}^{(2)}(k r \sqrt{ } \varepsilon)$. The relevant details can be found in the books by Wait [1962, 1970], Galejs [1972], Bliokh et al. [1980] and Nickolaenko and Hayakawa [2002].

The electromagnetic problem is solved for a system of thin horizontal layers of constant $\varepsilon$ for both upward going and down going radio waves. The continuity condition holds at each interface for the tangential fields. Thus, a system of linear algebraic equations is obtained for the amplitudes of waves within the layers. If one applies $N$ layers, the linear system contains $2 \mathrm{~N}$ equations. Such a treatment is regarded as the full wave solution, e.g., Wait [1970]. It was used in the Schumann resonance band by Knott [1998] and Jones and Knott [1999, 2003].

A more convenient variant of the full wave solution exploits the ratio of horizontal electric to horizontal magnetic field at each boundary, $\delta(r)$, i.e. the surface impedance. The problem is reduced to a nonlinear differential equation of the first order (Riccati equation), see, e.g., Wait [1970]. Its solution is constructed numerically using an iterative procedure [e.g., Hynninen and Galuk 1972, Bliokh et al. 1977, Galuk and Ivanov 1978, Bliokh et al. 1980, Galuk et al. 2015]. For the time dependence $\exp [+i \omega t]$, we obtain the following equation:

$$
\frac{d}{d r} \delta(r)-i k \varepsilon(r) \delta^{2}(r)+i k+\frac{v(v+1)}{i k r^{2} \varepsilon(r)}=0 .
$$

Here, $\delta(r)$ is the spherical surface impedance at the strata interface (see Nickolaenko and Hayakawa [2002], Chapter 2), $v(\omega)$ is the sought complex propagation constant, $\omega=2 \pi f$ is the circular wave frequency, $k=\omega / c$ is the wave number in free space, $c$ is the velocity of light in free space, and $r$ is the radius vector of the spherical coordinate system $(r, \theta, \varphi) ; \varepsilon(r)$ is the complex dielectric constant of the medium varying with height, and $\varepsilon_{0}$ is the permittivity of free space.

The operator of the problem is defined in the height interval from zero to infinity, and its eigen-value is $\lambda=v(v+1)$. At the perfectly conducting ground, the spherical surface impedance $\delta(a)=0$, where $a$ denotes the Earth's radius. This is the first boundary condition.

An ELF radio wave of frequency $f$ penetrates into the ionosphere and rapidly attenuates there, so that the plasma properties above some virtual altitude given by 
$r_{1}$ have only a very minor impact on the sub-ionospheric radio propagation. This altitude varies with frequency. However, it does not exceed the $100 \mathrm{~km}$ level: $r_{1}=a+100 \mathrm{~km}$. We may suggest that the ionosphere is vertically uniform above this $100 \mathrm{~km}$ altitude, and the surface impedance at $r_{1}$ is equal to $\delta\left(r_{1}\right)=\left[\varepsilon\left(r_{1}\right)\right]^{-1 / 2}$, where $\left|\varepsilon\left(r_{1}\right)\right|=$ const $>>1$. This is the second boundary condition for Equation (2).

The problem of finding the complex eigen-value is reduced to solving the equation

$$
\delta(a ; \lambda)=0
$$

with respect to the parameter $\lambda$. The $\delta(a ; \lambda)$ function is found by the numerical integration of Equation (2) from the top $r=r_{1}$ to the bottom $r=a$. The roots of the equation are found by iterations starting from $v=k a$.

Let $\lambda^{m}$ be the $m$-th iteration to the eigen-value $\lambda$; then the next, $m+1$, iteration is found by following Newton's procedure:

$$
\lambda^{m+1}=\lambda^{m}-\frac{\delta\left(a ; \lambda^{m}\right)}{\frac{\partial}{\partial \lambda} \delta\left(a ; \lambda^{m}\right)} .
$$

After obtaining the $(m+1)$-th iteration, we repeat the downward integration of Equation (2) along the radius with the new eigen-value, and thus we obtain the surface impedance at the ground for the next iteration. The initial value is: $\lambda^{0}=k a(k a+1)$. The iterations stop when the relative difference between the new and the previous eigen-value is smaller than $10^{-7}$. The derivative $\frac{\partial}{\partial \lambda} \delta(a ; \lambda)$ is found concurrently with the $\delta(r)$ function by integrating the differential equation for the function $\delta_{1}(r)=\frac{\partial}{\partial \lambda} \delta(r, \lambda)$. The relevant equation and the condition at $r=r_{1}$ are obtained by differentiation of Equation (2) with respect to the parameter $\lambda$ :

$$
\begin{gathered}
\frac{d}{d r} \delta_{1}(r)-2 i k \varepsilon(r) \delta(r) \delta_{1}(r)+\frac{1}{i k r^{2} \varepsilon(r)}=0 . \\
\delta_{1}(r)=0 .
\end{gathered}
$$

The upper height $r_{1}$ was established by an exhaustive search when the solutions were constructed for a set of $r_{1}$ values. Finally, the height $r_{1}=100 \mathrm{~km}$ was chosen since the relative change of the output eigenvalue did not exceed $10^{-7}$ when the starting height exceeded $100 \mathrm{~km}$. It is only above this height that the anisotropy of the ionosphere, which is due to the presence of the Earth's magnetic field [Madden and Thompson 1965, Rishbeth and Garriott 1969], becomes very important in determining the tensor value of the conductivity.
It is interesting to note that the approach described allows us to obtain not only the eigen-value of the zeroth mode in the Earth-ionosphere waveguide, but also the roots of the "trapped" higher order modes. Newton's method converges toward the eigen-value closest to the initial one. To treat the higher order modes, we have to exclude the roots of lower modes that have already been found. For this purpose we use Bézout's theorem [Korn and Korn 1968, Section 1.7.2]: the function

$$
\varphi_{n}=\frac{\varphi}{\prod_{i=1}^{n}\left(\varphi-\lambda_{i}\right)}
$$

is used in the process instead of the initial function $\varphi(\lambda)=0$, where $\lambda$ are the roots of the $\varphi(\lambda)$ function which have already been found, and $n$ denotes the number of these already established roots.

Prior to computing the ELF field components, we have to compute the so-called normalizing integrals. These are found automatically in the above scheme, as the following relation is valid:

$$
N^{0}=i k a^{2} \frac{\partial}{\partial \lambda} \delta(a ; \lambda)=i k a^{2} \delta_{1}(a) .
$$

The normalizing integral $N^{0}$ allows us to obtain the lower characteristic height of the Earth-ionosphere cavity [Kirillov 1993, Kirillov 1996, Kirillov et al. 1997, Kirillov and Kopeykin 2002]:

$$
H_{C}(f) \cong \int_{0}^{\infty} \frac{d h}{1-i \sigma(h) / \omega \varepsilon_{0}}=i k a^{2} \delta_{1}(a) .
$$

(Heights which are complex quantities are shown as capital (upper case) letters, to emphasize this fact). This characteristic height is regarded as the "capacitance", or the "electric", height of the Earth-ionosphere system:

$$
H_{C}(\theta)=\frac{1}{E_{r}(a, \theta)} \int_{a}^{\infty} E_{r}(a, \theta) d r .
$$

It is used when obtaining the capacitance elements of the artificial two-dimension RLC circuit of the Earth-ionosphere cavity resolved with the help of the 2D telegraph equations [Madden and Thompson 1965, Kirillov 1993, Kirillov 1996, Kirillov et al. 1997, Kirillov and Kopeykin 2002, Pechony and Price 2004, Pechony 2007] or in the approximate formulas for the ELF propagation constant [Greifinger and Greifinger 1978, Nickolaenko and Rabinowicz 1982, Mushtak and Williams 2002].

The upper characteristic height, the "inductance" (or the "magnetic") height 


$$
H_{L}(\theta)=\frac{1}{H_{\varphi}(a, \theta)} \int_{0}^{\infty} \frac{r}{a} H_{\varphi}(r, \theta) d r
$$

is introduced by using the relation:

$$
v(v+1)=H_{L} / H_{C} .
$$

Heights $H_{C}$ and $H_{L}$ are physically equivalent to the now popular electric and magnetic characteristic heights $h_{E}$ and $h_{M}$. These are the altitudes above which the relevant fields start to rapidly decrease. The distinction is that heights $H_{C}$ and $H_{L}$ are found from the rigorous full wave solution, which exploits the continuous conductivity profile, while the characteristic heights $h_{E}$ and $h_{M}$ are introduced by the approximate heuristic relations [e.g., Mushtak and Williams 2002, Williams et al. 2006]. To stress this distinction, we use different notations for the heights.

The standard description for sub-ionospheric radio wave propagation in the extremely low frequency band (ELF: $3 \mathrm{~Hz}-3 \mathrm{kHz}$ ) uses the propagation constant $v(f)$, the source-observer distance $\theta$, and the current moment of the dipole source $M_{C}(f)$. The relevant equations can be found in Nickolaenko and Hayakawa $[2002,2014]$. We use here the commonly accepted standard frequency dependence $v(f)$ suggested by Ishaq and Jones [1977], which incorporated the vast collection of experimental material from the global array of the Schumann resonance observatories available at that time. According to this model, the complex propagation constant $v(f)$ is found from the following heuristic equations presented by Ishaq and Jones [1977]:

$v(f)=\left[0.25+(k a S)^{2}\right]^{1 / 2}-0.5$,

$S=c / V-i 5.49 \alpha / f$,

$c / V=1.64-0.1759 \ln (f)+0.01791[\ln (f)]^{2}$,

$\alpha=0.063 f^{0.64}$

where $v$ is the dimensionless ELF propagation constant, $S$ is the complex sine function relevant to Brillouin waves in the Earth-ionosphere cavity [e.g., Wait 1970], $V$ and $c$ are the phase velocity of radio wave and velocity of light, respectively, the parameter $\alpha$ which accounts for the wave attenuation is in Napier/radian, and $f$ is measured in $\mathrm{Hz}$.

Figure 3 shows frequency variations of the imaginary part of the propagation constant, or the losses in uniform cavity. We must remind the reader here that we take into account only the vertical (radial) non-uniformity of ionosphere. The real ionosphere is characterized by the day-night boundary and the polar non-uniformity, and the plasma becomes an anisotropic medium above $\sim 80 \mathrm{~km}$ altitude. All these features are ignored at present, as our goal is only to present an average (on the global scale) $\sigma(h)$ profile, which is in reasonable agreement with both DC and AC observations and models. Accounting for the above mentioned details is a possible area of demanding future work.

It is interesting to note in this regard that recent satellite observations have demonstrated the presence of Schumann resonance signals in the topside ionosphere [Simoes et al. 2011, Dudkin et al. 2015], indicating that energy is being lost from the cavity, even though this is inconsistent with considerations of $r_{1}$ discussed earlier. This indicates that an explanation of the space-borne observations of sub-ionospheric Schumann resonances should be based on the possible in-

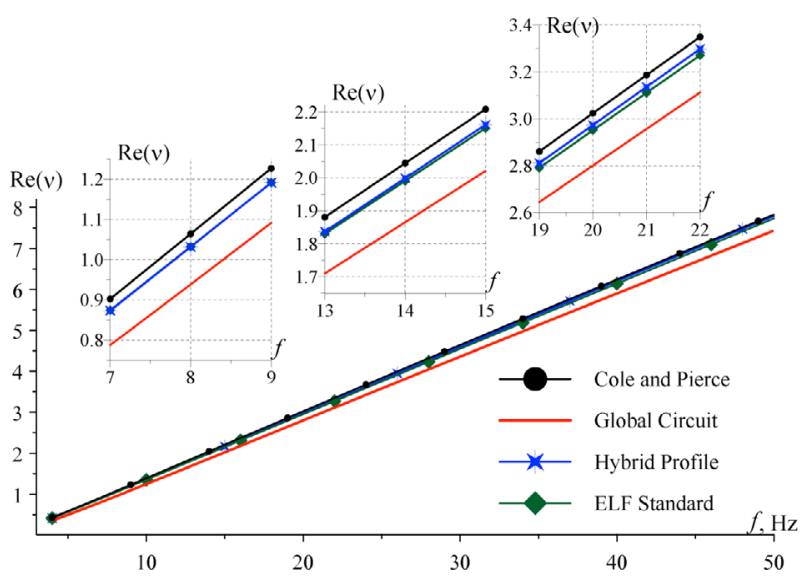

Figure 2. Real parts of the ELF propagation constant obtained with the full wave solution for the Cole and Pierce [1965] profile (black line with dots); profile based on the global circuit data (red smooth line); the hybrid profile (blue curve with stars). These are compared with the reference model (green curve with diamonds).

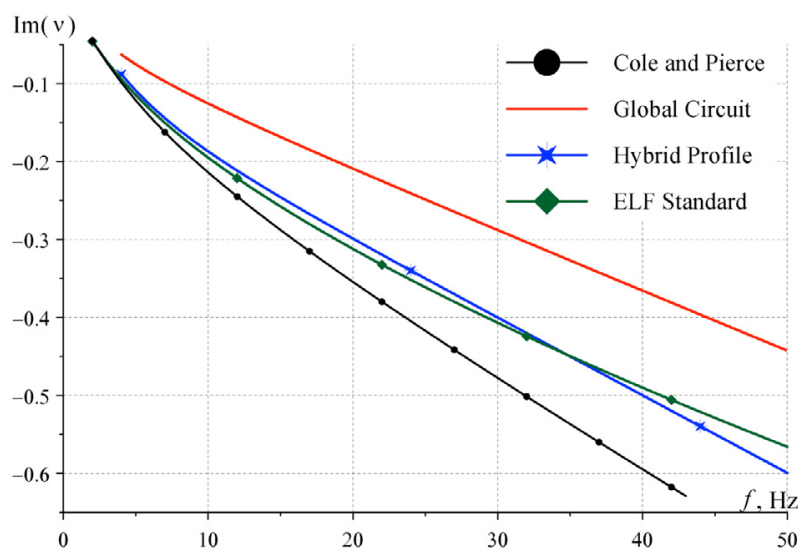

Figure 3. Imaginary part of the ELF propagation constant obtained with the full wave solution for the Cole and Pierce [1965] profile (black line with dots); profile based on the global circuit data (red smooth line); the hybrid profile (blue curve with stars). The ELF Standard reference model (Equations 10 to 13) is shown by the green curve with diamonds. 
fluence of ionospheric anisotropy on ELF propagation through the plasma. Consider a sub-ionospheric transverse electromagnetic (TEM) wave entering the ionospheric plasma; its magnetic field reaches the altitude of $80-90 \mathrm{~km}$ where the plasma anisotropy becomes important. Here, the electromagnetic wave transforms into an ELF hydromagnetic wave that penetrates up to satellite altitudes, as was mentioned by Madden and Thompson [1965] in their seminal paper which contains rigorous numerical computations for both day and night conditions. The theoretical treatment of Madden and Thompson [1965] estimated that one third of the Schumann resonance energy escapes from the cavity at night, that the "ionisation levels at around 40-50 km are very important for the Schumann resonances" and that most damping occurs near these heights. They also stated that "conduction currents dominate over the displacement currents above about $60 \mathrm{~km}$ ". Further, they mentioned that dust from meteor showers could influence Schumann resonances.

The full wave solutions of Madden and Thompson [1965] are obtained only at altitudes above about 25 $\mathrm{km}$. Below this altitude, of great relevance for the global circuit, their system of linear algebraic equations cannot obtain the reflection and transmission coefficients at the interfaces between different slabs. That is why we have used the Riccati equation for the surface impedance [Bliokh et al. 1977], which works below $25 \mathrm{~km}$.

The models of the imaginary part of the propagation constant provide different results here. The values deduced from parameters of the night-time DC global circuit (red curve) result in the smallest radio wave attenuation. The black line with dots based on the Cole and Pierce [1965] daytime model shows the highest attenuation rate. The ELF Standard reference model (green line with diamonds) is rather close to the blue line with stars computed for the hybrid (global average, over all local times) conductivity profile, which is introduced in this paper.

The plots presented in Figure 2 and Figure 3 indicate that the red profile describing the leakage current between the Earth and the ionosphere (the DC circuit) overestimates the phase velocity of radio wave and underestimates the ELF attenuation rate. In contrast, the Cole and Pierce [1965] profile underestimates the phase velocity and the Schumann resonance frequencies correspondingly, and it overestimates the ELF attenuation rate.

Physically this means that the real conductivity at altitudes $\sim 50 \mathrm{~km}$ and above is somewhat higher than DC model predicts and lower than that of classical conductivity profile. However, such a detail could not be sensed in the static electric field within the tropo- sphere where the major part of the ionosphere-toground potential difference exists; only Schumann resonance parameters are sensitive to the conductivity at this altitude.

The very small modifications of the DC electric field at ground level are within the measurement accuracy and within the variations with Universal Time, known as the Carnegie curve [Harrison 2013]. If we turn to the Earth-ionosphere leakage current, changes in the air conductivity around $50 \mathrm{~km}$ altitude definitely will not alter the fair weather field at the ground. It is only at the "electrosphere", the height where "horizontal spreading" of the current occurs, that will be reduced from, say, 70 to $60 \mathrm{~km}$.

The classical conductivity profile presented by Cole and Pierce [1965] overestimates the losses in the cavity. To match the ELF Standard propagation model, we have to slightly increase the air conductivity starting from the stratosphere. In this case the blue curve is obtained as being very close to the ELF Standard model.

\section{Power spectra for globally uniform distribution of lightning strokes}

The dispersion curves of Figure 2 and Figure 3 allow us to compute the power spectral density of the vertical electric field in the Schumann resonance band, which was first observed experimentally by Balser and Wagner [1960]. The resonance pattern depends on the source-observer distance. To eliminate any influence of this factor, we apply a globally uniform spatial distribution of lightning strokes [Bliokh et al. 1977, Bliokh et al. 1980, Sentman 1995, Sentman 1996, Nickolaenko and Hayakawa 2002, Williams et al. 2006, Nickolaenko and Hayakawa 2014]. We suggest that independent random lightning strokes occur with the same probability at any point of the globe, i.e., the probability density of the source coordinates is the constant:

$$
\mathcal{w}(\theta, \varphi)=\frac{1}{4 \pi}
$$

Electromagnetic radiation from global thunderstorms forms a random succession of independent ELF pulses at the radio receiver, and the delay of the pulse arrival times is supposed to have an exponential distribution. In this case we speak of a Poisson random process [Middleton 1960, Korn and Korn 1968 (Section 18.11.5), Tikhonov 1982]. The mutual interference of pulses disappears in the averaged power spectrum of such a process, and "individual power spectra of pulses are summed". The resulting power spectrum of the vertical electric field is found from the following equation: 


$$
<|E(f)|^{2}>\propto\left|\frac{v(v+1)}{2 \pi f}\right|^{2} \sum_{n=0}^{\infty} \frac{2 n+1}{|n(n+1)-v(v+1)|^{2}},
$$

where $n=0,1,2,3 \ldots$ is the Schumann resonance mode number. The series in Equation (16) was obtained by integrating the probability density (15) multiplied by the product of two zonal harmonic series for the electric field (see Bliokh et al. [1980], Nickolaenko and Hayakawa [2002], Nickolaenko and Hayakawa [2014], for details). The series (16) converges rather fast, and the computations are simple.

Figure 4 shows the power spectra given by (16) computed for the three propagation constants $v(f)$, except the one relevant to the Cole and Pierce [1965] profile. The abscissa here shows the frequency ranging from 4 to $50 \mathrm{~Hz}$, and the ordinate depicts the power spectral density in arbitrary units. We may note that the Schumann resonance pattern is clearly observed in all graphs. As was expected, the maxima of the red curve occur at higher frequencies, and this is explained by the higher values of $\operatorname{Re}[v(f)]$ noted in Figure 2 . Owing to the smaller attenuation factor (Figure 3 ), the peaks of the red resonance curve (based on the DC global circuit model) have smaller widths in comparison with those for the standard black spectrum and for the global hybrid profile (blue line).

The green and blue lines in Figure 4 are close to each other in the vicinity of the first three resonance modes (i.e. for $n=0,1,2,3)$. This is explained by the proximity of the relevant lines in Figure 2 and Figure 3. However, we notice that the resonance pattern is more sensitive to the slight deviations in the dispersion curves. Indeed, the green and blue lines of $\operatorname{Re}[v(f)]$ functions (phase velocities) are almost coincident in Figure 2, while the positions of the spectral peaks are obviously different in Figure 4. Deviations in the phase velocity and in the wave attenuation cause the evident differences between the green and

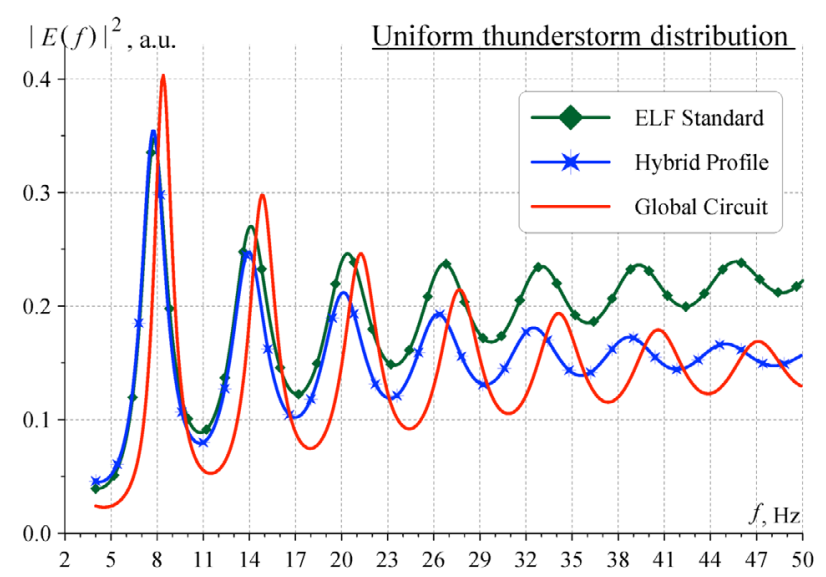

Figure 4. Power spectra of vertical electric field in arbitrary units (see text for a full explanation). blue spectra, especially at the higher modes $n \geq 4$. This indicates that the hybrid profile does not exactly match the standard ELF propagation model.

Such deviations are quite acceptable from the practical point of view, as only three Schumann resonance modes are clearly observed in the experimental records and are used in interpretations. Of course, this does not mean that a better conductivity profile might be constructed that fits the standard spectrum (and observations) in a better way.

When comparing the red (the DC data) and blue (AC data) spectra in Figure 4, we note obvious deviations. These are due to differences between the profiles within the middle atmosphere. The global electromagnetic resonance is sensitive to the conductivity in the mesosphere and thus it can be used for selecting the models based on the DC ground-based observations.

\section{Discussion}

The validity of the vertical profiles of atmospheric conductivity at different altitudes might be checked by measurements of the low frequency electromagnetic fields and of the fair weather field observed in the troposphere and at ground level [e.g., Harth 1982, Holzworth and Chiu 1982, Holzworth 1991, 1995]. The ELF/ VLF radio waves are particularly sensitive to the properties of the ionosphere over narrow ( $\sim$ few $\mathrm{km}$ ) height ranges between 50 and $120 \mathrm{~km}$ [Galejs 1961, Wait 1962, Madden and Thompson 1965, Wait 1970, Galejs 1972], whereas the fair weather field mainly depends on the conductivity of the troposphere [e.g., Ogawa 1985, Rycroft et al. 2007, Rycroft et al. 2008]. Schumann resonance signals "sense" the conductivity in the range of heights from $\sim 40$ to $\sim 100 \mathrm{~km}$ and therefore their interpretation can contribute to the information derived from the sparse data derived from different observations.

The applicability of the blue conductivity profile can be verified by comparing the wave attenuation with direct measurements of monochromatic radio signals from ELF transmitters [Bannister 1999, Nickolaenko 2008]. Data used in the paper by Bannister [1999] exploit the amplitude monitoring of ELF signals from the US Navy transmitter, regarded as the Wisconsin test facility (WTF). The average attenuation at the $76 \mathrm{~Hz}$ frequency was equal to $1.08 \mathrm{~dB} / \mathrm{Mm}$, and the relative standard deviation due to seasonal variations was $\pm 25 \%$.

The imaginary part of the propagation constant at this frequency for the hybrid profile is equal to $\operatorname{Im}[v(f)]_{f=76 \mathrm{~Hz}}=0.86 \mathrm{Napier} / \mathrm{radian}$, and this value corresponds to the attenuation factor $\gamma(76 \mathrm{~Hz})=1.17$ $\mathrm{dB} / \mathrm{Mm}$. This attenuation is practically coincident with observations, and this fact is certainly in favour of the model. 
The wave attenuation measured at $82 \mathrm{~Hz}$ was also published by Nickolaenko [2008]. It was equal to $\operatorname{Im}[v(f)]_{f=82 \mathrm{~Hz}}=0.92 \mathrm{Napier} /$ radian, which corresponds to the attenuation factor $\gamma(82 \mathrm{~Hz})=1.25 \mathrm{~dB} / \mathrm{Mm}$. This attenuation rate was inferred from the distance dependence of the signal amplitude detected in the vertical electric field of the radio wave emitted by the Soviet Kola Peninsula transmitter [Velikhov 2014]. The model attenuation is exactly equal to the value measured experimentally. Thus, the comparison with observations of man-made ELF radio transmissions supports the validity of the hybrid conductivity profile very well.

We now evaluate the value of the fair weather field for the three conductivity profiles. The altitude variations of atmosphere conductivity $\sigma(h)$ shown in Figure 1 were transformed into the air resistance $\rho(h)=1 / \sigma(h)$ for this purpose. The relevant plots are shown in the upper frame of Figure 5 for all three model profiles. The smooth red curve shows the global circuit model of Rycroft et al. [2007], and the blue and black lines depict profiles pertinent to the hybrid model and to the classical Cole and Pierce [1965] profile, respectively. The upper plot in Figure 5 indicates that the resistance of the air column having $1 \mathrm{~m}^{2}$ cross-section varies from $10^{14}-10^{13} \mathrm{Ohm} \mathrm{m}$ at the ground to about $10^{10} \mathrm{Ohm} \mathrm{m}$ at around $40 \mathrm{~km}$ altitude. The values obtained for the different models vary by about one order of magnitude.

Plots in the lower frame of Figure 5 depict the voltage drop across a $1 \mathrm{~m}$ gap in the air (the strength of the fair weather field at different altitudes) corresponding to the three conductivity profiles. These values are readily obtained using Ohm's law, by multiplying the air resistance $\rho(h)=1 / \sigma(h)$ by the leakage current of global circuit of $j=1.3 \mathrm{pA} / \mathrm{m}^{2}$ [Rycroft et al. 2000]. The relevant fair weather field at ground level becomes equal to 86 $\mathrm{V} / \mathrm{m}$ in the hybrid and the global circuit models and 12 $\mathrm{V} / \mathrm{m}$ in the Cole and Pierce [1965] model. If we integrate the voltage drop with altitude, we find that the ionosphere-to-ground potential difference, $\mathrm{V}_{\mathrm{I}}$, is equal to 247 $\mathrm{kV}$ for the hybrid model, $263 \mathrm{kV}$ for the Rycroft et al. [2007] model, but only $61 \mathrm{kV}$ for the Cole and Pierce [1965] profile. That value is unrealistically low, due to the large daytime conductivity values of that profile.

The resistance profile based on the conductivity of the global circuit model of Rycroft et al. [2007] proved to be useful in elaborating the source of a parametric Q-burst [Nickolaenko 2011] caused by the giant galactic gamma-ray flare that arrived from the magnetar SGR 1806-20 at Earth at 21:30:26 U.T. on December 27,2004 . The illuminated hemisphere was practically coincident with the dayside of the globe: the sub-flare point was only $450 \mathrm{~km}$ away from the centre of the daytime hemisphere.
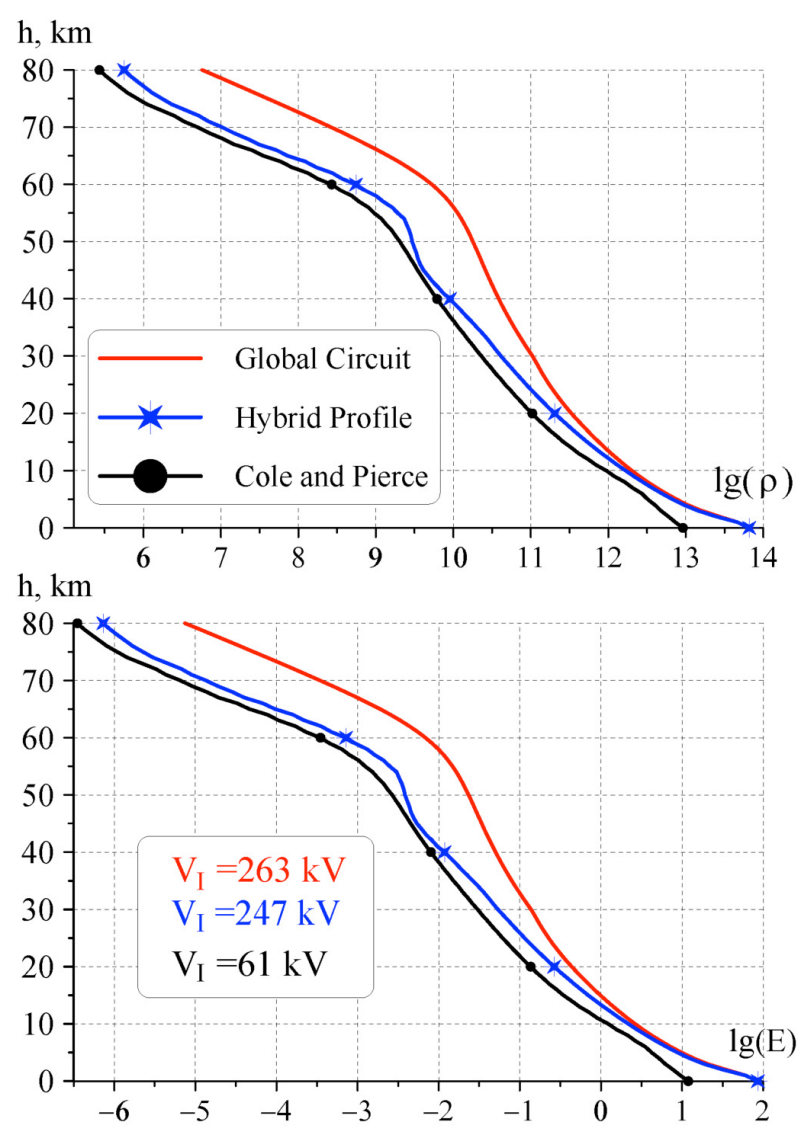

Figure 5. Altitude profiles of the air resistance (upper plot, in Ohm $\mathrm{m}$ ) and fair weather field amplitude (in $\mathrm{V} / \mathrm{m}$, lower plot). The corresponding value of the ionospheric potential $V_{\mathrm{I}}$ is shown in the legend for the lower plot found in the Rycroft et al. [2007] model, for the hybrid model presented here, and for the Cole and Pierce [1965] model (CP). The value derived for the latter model is certainly far too low, whereas the small discrepancy between the red and blue values is within the range of variations with Universal Time on a particular day and within the observed day-to-day variability.

The gamma-flare also transformed the Schumann resonance spectra for a short time [Nickolaenko et al. 2010, Tanaka et al. 2011]. Feasible "parametric" pulsed excitation of the Earth-ionosphere cavity was predicted [Nickolaenko 2011] caused by modification of the global electric circuit. Such a source deviates from the ordinary lightning strokes, which excite Schumann resonances, and the major features of ELF transient are conditioned by the great horizontal size of the modification to the cavity, covering almost a hemisphere. Such a coherent source drives only the lowest modes of Schumann resonance, and this was confirmed experimentally [Nickolaenko et al. 2010, Schekotov et al. 2013, Nickolaenko et al. 2014].

In modeling the parametric ELF source, VLF information was also used, being relevant to the particular gamma-flare; the lower edge of the dayside ionosphere fell suddenly from 60 to $40 \mathrm{~km}$ as a result of ionisation produced in the mesosphere and upper stratosphere [Inan et al. 2007]. The modification covered the whole 
of the Pacific Ocean, and it was recorded at the Antarctic Palmer Station for different VLF paths up to $60^{\circ}$ from the sub-flare point. The modification of the air resistance was estimated by using the conductivity profile of Rycroft et al. [2007] as a starting model for several modifications [Nickolaenko 2011]. Computations indicated that changes below the tropopause were definitely important for the source current of the parametric ELF transient. The final model provided a sudden increase of the Earth-ionosphere leakage current from 1 $\mathrm{pA} / \mathrm{m}^{2}$ to $6 \mathrm{pA} / \mathrm{m}^{2}$ associated with the two-fold reduction of the air resistance at ground level (the modification of air conductivity increased linearly with altitude). We do not know whether there are any experimental observations, which could confirm or negate this prediction of a much increased fair weather conduction current density during this most unusual event.

\section{Conclusions}

We have shown here that a model for the globally averaged height profile of air conductivity which is a hybrid (blue curve) between the early Cole and Pierce [1965] daytime profile (black curve) and the empirical night-time profile (red curve) used in a model of the DC global electric circuit by Rycroft et al. [2007] satisfies both observations of Schumann resonance (AC global circuit properties) and fair weather observations of the electric field throughout the atmosphere (DC global circuit properties) very well. The crucial height regions for the DC part are the lowest $15 \mathrm{~km}$, i.e. the troposphere; around the knee in the profile at $\sim 55 \mathrm{~km}$ altitude is most crucial for the AC part. This new hybrid model leads to a realistic variation of the electric field strength through the fair weather regions of the atmosphere and to a realistic value of the potential of the ionosphere with respect to the Earth's surface, namely $V_{I}=247 \mathrm{kV}$. This value fits within the range observed by Markson [2007]. We suggest that this hybrid profile, a global profile which harmonises $\mathrm{AC}$ and DC profiles, which is in overall agreement with many different types of observations - but not those associated with aerosols and showing a sharp conductivity ledge from 84 to $86 \mathrm{~km}$ altitude at some locations and at some times - should be useful in future studies of both $\mathrm{AC}$ and DC global circuit phenomena.

Acknowledgements. The authors are most grateful to many colleagues in different countries for sharing their ideas on the topics discussed here, and especially to the referee for raising several points which necessitated further consideration and clarification before publication.

\section{References}

Balser, M., and C. Wagner (1960). Observations of Earth-ionosphere cavity resonances, Nature, 188,
638-641.

Bannister, P.R. (1999). Further examples of seasonal variations of ELF radio propagation parameters, Radio Sci., 34, 199-208.

Bliokh, P.V., Yu.P. Galuk, E.M. Hynninen, A.P. Nickolaenko and L.M. Rabinowicz (1977). On the resonance phenomena in the Earth-ionosphere cavity, Izv. VUZOV, Radiofizika, 20 (14), 501-509, (in Russian).

Bliokh, P.V., A.P. Nickolaenko and Yu. F. Filippov (1980). Schumann resonances in the Earth-ionosphere cavity, D. Ll. Jones (ed.), Peter Peregrinus, New York, London, Paris, $168 \mathrm{p}$.

Chapman, F., and D. Jones (1964). Earth-ionosphere cavity resonances and the propagation of extremely low frequency radio waves, Nature, 202, 654-657.

Cole, R.K., and E.T. Pierce (1965). Electrification in the Earth's atmosphere from altitudes between 0 and 100 kilometers, J. Geophys. Res., 70, 2735-2749.

Croskey, C.L., L.C. Hale and J.D. Mitchell (1990). Electrical stratification in the middle atmosphere, Adv. Space Res., 10, 49-52.

Curto, J.J., L.F. Alberca, R.H. Holzworth, B. de la Morena, J. Battlo, J.G. Sole and D. Altadill (2001). Electric conductivity and electric field in the stratosphere: Middle-latitude balloon flight results, J. Geophys. Res., 106, 21337-21342.

Dudkin, F., V. Korepanov, D. Dudkin, V. Pilipenko, V. Pronenko and S. Klimov (2015). Electric field of the power terrestrial sources observed by microsatellite Chibis-M in the Earth's ionosphere in frequency range 1-60 Hz, Geophys. Res. Lett., 42, 5686-5693; doi:10.1002/2015GL064595.

Dyrda, M., A. Kulak, J. Mlynarczyk and M. Ostrowski (2015). Novel analysis of a sudden ionospheric disturbance using Schumann resonance measurements, J. Geophys. Res., 120, 2255-2262; doi:10.1002/2014J A020854.

Friedrich, M., and K.M. Torkar (2001). FIRI: A semiempirical model of the lower ionosphere, J. Geophys. Res., 106, 21409-21418; doi:10.1029/2001JA900070.

Friedrich, M., and M. Rapp (2009). News from the lower ionosphere: A review of recent developments, Surv. Geophys., 30, 525-559.

Friedrich, M., K.M. Torkar, U.-P. Hoppe, T.-A. Bekkung, A. Barjatya and M. Rapp (2013). Multi-instrument comparisons of D-region plasma measurements, Annales Geophysicae, 31, 135-144.

Fullekrug, M. (2000). Dispersion relation for spherical electromagnetic resonances in the atmosphere, Physics Letters A, 275, 80-89.

Fullekrug, M., A.C. Fraser-Smith and K. Schlegel (2002). Global ionospheric D-layer height monitoring, Europhys. Lett., 59, 626-632. 
Fullekrug, M. (2005). Detection of thirteen resonances of radio waves from particularly intense lightning discharges, Geophys. Res. Lett., 32, L13809; doi:10.1 029/2005GL023028.

Fullekrug, M., E. Mareev and M. Rycroft, eds. (2006). Sprites, elves and intense lightning discharges, vol. 225, Springer, Dordrecht, The Netherlands, 398 p.

Galejs, J. (1961). Terrestrial extremely low frequency noise spectrum in the presence of exponential ionospheric conductivity profiles, J. Geophys. Res., 66, 2789-2793.

Galejs, J. (1965). Schumann resonances, J. Res. NBS, 69D, 1043-1055.

Galejs, J. (1972). Terrestrial propagation of long electromagnetic waves, Pergamon Press, New York, 362 p.

Galuk, Yu.P., and V.I. Ivanov (1978). Deducing the propagation characteristics of VLF fields in the cavity Earth - non-uniform along the height anisotropic ionosphere, in Problems of diffraction and radio wave propagation, Leningrad State University, 16, 148-153 (in Russian).

Galuk, Yu.P., M. Hayakawa and A.P. Nickolaenko (2015). Knee model: comparison between heuristic and rigorous solutions for the Schumann resonance problem, J. Atmos. Sol.-Terr. Phys., 135, 85-91, 13646826; doi:10.1016/j.jastp.2015.10.008.

Greifinger, C., and P. Greifinger (1978). Approximate method for determining ELF eigenvalues in the Earth-ionosphere waveguide, Radio Sci., 13, 831837.

Greifinger, P.S., V.C. Mushtak and E.R. Williams (2007). On modeling the lower characteristic ELF altitude from aeronomical data, Radio Sci., 42, RS2S12; doi:10.1029/2006RS003500.

Hale, L.C., C.L. Croskey and J.D. Mitchell (1981). Measurements of middle-atmospheric electric fields and associated electrical conductivity, Geophys. Res. Lett., 8, 927-931.

Hale, L.C. (1984), Middle atmosphere electrical structure, dynamics, and coupling, Adv. Space Res., 4, 175-186.

Han, F., S.A. Cummer, J. Li and G. Lu (2011). Daytime ionospheric $\mathrm{D}$ region sharpness derived from VLF radio atmospherics, J. Geophys. Res., 116, A05314; doi:10.1029/2010JA016299.

Harrison, R.G. (2013). The Carnegie curve, Surv. Geophys., 34, 209-232.

Harrison, R.G., K.A. Nicoll and K.L. Aplin (2014). Vertical profile measurements of lower troposphere ionisation. J. Atmos. Sol.-Terr. Phys., 119, 203-210; doi:10.1016/j.jastp.2014.08.006.

Harth, W. (1982). Theory of low frequency wave propagation, In: H. Volland (ed.), CRC Handbook of At- mospherics, vol. 2, CRC Press Inc., Boca Raton, Florida, 134-203.

Hays, P.B., and R.G. Roble (1979). A quasi-static model of global atmospheric electricity, 1 . The lower atmosphere, J. Geophys. Res., 84, 3291-3305.

Holzworth, R.H., and Y.T. Chiu (1982). Spherics in the stratosphere, In: H. Volland (ed.), CRC Handbook of Atmospherics, vol. 2, CRC Press Inc., Boca Raton, Florida, 2-19.

Holzworth, R.H. (1991). Conductivity and electric field variations with altitude in the stratosphere, J. Geophys. Res., 96, 12857-12864.

Holzworth, R.H. (1995). Quasistatic Electromagnetic Phenomena in the Atmosphere and Ionosphere, In: H. Volland (ed.), CRC Handbook of Atmospherics, CRC Press Inc., Boca Raton, Florida, 235-266.

Huang, E., E. Williams, R. Boldi, S. Heckman, W. Lyons, M. Taylor, T. Nelson and C. Wong (1999). Criteria for sprites and elves based on Schumann resonance observations, J. Geophys. Res., 104, 1694316964.

Hynninen, E.M., and Yu.P. Galuk (1972). Field of vertical dipole over the spherical Earth with non-uniform along height ionosphere, in Problems of diffraction and radio wave propagation, Leningrad State Universtity, 11, 109-120 (in Russian).

Inan, U.S., N.G. Lehtinen, R.C. Moore, K. Hurley, S. Boggs, D.M. Smith and G.J. Fishman (2007). Massive disturbance of the daytime lower ionosphere by the giant gamma-ray flare from magnetar SGR 1806-20, Geophys. Res. Lett., 34, L08103; doi:10.10 29/2006GL029145.

Ishaq, M., and D.Ll. Jones (1977). Method of obtaining radiowave propagation parameters for the Earthionosphere duct at ELF, Electronic Lett., 13, 254255.

Jones, D.Ll. (1976). Schumann resonances and E.L.F. propagation for inhomogeneous isotropic ionospheric profiles, J. Atmos. Terr. Phys., 29, 1037-1044.

Jones, D.Ll., and M. Knott (1999). Comparison of simplified and full-wave ELF propagation models, Abstracts of Reports at URSI General Assembly, Toronto, Session E6, August 1999.

Jones, D.Ll., and M. Knott (2003). Computations of electromagnetic resonance in the Earth-ionosphere cavity using full wave solution and approximate model, Radio-Physics and Electronics, 8, 55-66 (in Russian).

Kero, A., J. Vierinen, D. McKay-Bukowski, C.-F. Enell, M. Sinor, L. Roininen and Y. Ogawa (2014). Ionospheric electron density profiles inverted from a spectral riometer measurement, Geophys. Res. Lett., 41, 5370-5375; doi:10.1002/2014GL060986. 
Kirillov, V.V (1993). Parameters of the Earth-ionosphere waveguide at ELF, In: Problems of radio wave diffraction and propagation, Leningrad State Universtity, 23, 35-52 (in Russian).

Kirillov, V.V (1996). 2D theory of ELF electromagnetic wave propagation in the Earth-ionosphere cavity, Izv. VUZOV, Radiofizika, 39, 1103-1112 (in Russian).

Kirillov, V.V., V.N. Kopeykin and V.C. Mushtak (1997). Electromagnetic waves of ELF band in the Earthionosphere cavity, Geomagn. Aeron., 37, 114-120 (in Russian).

Kirillov, V.V., and V.N. Kopeykin (2002). Solution of 2D telegraph equations with anisotropic parameters, Izv. VUZOV Radiofizika, 45, 1011-1024 (in Russian).

Knott, M. (1998). Computations of ELF EM Fields in the Earth-Ionosphere Duct. Report, Physics Dept., King's College, London, 45 p.

Korn, G.A., and T.M. Korn (1968). Mathematical Handbook, second edition, McGraw-Hill, New York, San Francisco, Toronto, Sydney, 831 p.

Kulak, A., J. Kubisz, A. Michalec, S. Zięba and Z. Nieckarz (2003). Solar variations in extremely low frequency propagation parameters: 2 . Observations of Schumann resonances and computation of the ELF attenuation parameter, J. Geophys. Res., 108, 1271-1279; doi:10.1029/ 2002JA009305.

Madden, T., and W. Thompson (1965). Low frequency electromagnetic oscillations of the Earth-ionosphere cavity, Rev. Geophys., 3, 211-254.

Makino, M., and T. Ogawa (1984). Responses of atmospheric electric field and air-earth current to variations of conductivity profile, J. Atmos. Terr. Phys., 46, 431-445.

Makino, M., and T. Ogawa (1985). Quantitative estimation of global circuit, J. Geophys. Res., 90, 5961-5966.

Markson, R. (2007). The global circuit intensity: Its measurement and variation over the last 50 years, Bull. Am. Meteorol. Soc., 88, 223-241.

McNeil, W.J., S.T. Lai and E. Murad (1998). Differential ablation of cosmic dust and implications for the relative abundances of atmospheric metals, J. Geophys. Res., 103, 10899-10911.

Mechtly, E.A., S.A. Bowhill and L.G. Smith (1972). Changes of lower ionosphere electron concentrations with solar activity, J. Atmos. Terr. Phys., 34, 1899-1907.

Middleton, D. (1960), An Introduction to Statistical Communication Theory, vol. 1, ch. 11.2-2, McGrawHill, New York, San Francisco, Toronto, Sydney.

Mushtak, V.C., and E.R. Williams (2002). ELF propagation parameters for uniform models of the Earthionosphere waveguide, J. Atmos. Sol.-Terr. Phys., 64, 1989-2001.
Nickolaenko, A.P., and L.M. Rabinowicz (1982). Possible global electromagnetic resonances on the planets of the solar system, translated from Kosmicheskie Issledovaniya, vol. 20, No. 1, Plenum Publishing Corporation, 82-88.

Nickolaenko, A.P., and M. Hayakawa (2002). Resonances in the Earth-ionosphere cavity, Kluwer Academic Publishers, Dordrecht, Boston, London, 380 p.

Nickolaenko, A.P. (2008). ELF attenuation factor derived from distance dependence of radio wave amplitude propagating from an artificial source, Telecomm. Radio Eng+, 67, 1621-1629.

Nickolaenko, A.P., I.G. Kudintseva, O. Pechonaya, M. Hayakawa, T. Nakamura, Y. Hobara and Y. Tanaka (2010). Impact of a gamma-ray burst on the Schumann resonance, Radiophys. Quantum El., 53 (9/10), 542-556; doi:10.1007/s11141-011-9249-9.

Nickolaenko, A.P. (2011). Source models for "parametric” Q-burst, Journal of Atmospheric Electricity, 31, 95-110.

Nickolaenko, A., and M. Hayakawa (2014). Schumann Resonance for Tyros (Essentials of Global Electromagnetic Resonance in the Earth-Ionosphere Cavity), Springer, Geophysics Series XI, 348 p.

Nickolaenko, A.P., A.Yu. Schekotov, M. Hayakawa, Y. Hobara, G. Sátori, J. Bor and M. Neska (2014). Multipoint detection of the ELF transient caused by the gamma flare of December 27, 2004, Radiophys. Quantum El., 57, 125-140.

Nickolaenko, A.P., Yu.P. Galuk and M. Hayakawa (2016), Vertical profile of atmospheric conductivity that matches Schumann resonance observations, SpringerPlus, 5, 108, doi:10.1186/s40064-016-1742-3.

Odzimek, A., M. Lester and M. Kubicki (2010). EGATEC: A new high-resolution engineering model of the global atmospheric electric circuit - Currents in the lower atmosphere, J. Geophys. Res., 115, D18; doi:10.1029/2009JD013341.

Ogawa, T. (1985). Fair weather electricity, J. Geophys. Res., 90, 5951-5961.

Otsuyama, T., D. Sakuma and M. Hayakawa (2003). FDTD analysis of ELF wave propagation and Schumann resonances for a subionospheric waveguide model, Radio Sci., 38, 1103; doi:10.1029/2002RS00 2752.

Park, C.G., and M. Dejnakarintra (1973). Penetration of thundercloud electric fields into the ionosphere and magnetosphere: 1. Middle and subauroral latitudes, J. Geophys. Res., 78, 6623-6633; doi:10.1029/J A078i028p06623.

Pavlov, A.V (2014). Photochemistry of ions at D-region altitudes of the ionosphere: a review, Surv. Geophys., 35, 259-334; doi:10.1007/s10712-013-9253-z. 
Pavlov, A.V (2016). Influence of atmospheric solar radiation absorption on photodestruction of ions at D-region altitudes of the ionosphere, Surv. Geophys., 37; doi:10.1007/s10712-016-9371-5.

Pechony, O. (2003). Modeling and Simulations of Schumann Resonance Parameters Observed at the Mitzpe Ramon Field Station, Ph.D. Thesis, Tel-Aviv University, Israel, $92 \mathrm{p}$.

Pechony, O., and C. Price (2004). Schumann resonance parameters computed with a partially uniform knee model on Earth, Venus, Mars and Titan, Radio Sci., 39, RS5007; doi:10.1029/2004RS003056.

Plane, J.M.C. (2003). Atmospheric chemistry of meteoric metals, Chem. Rev., 103, 4963-4984.

Polk, C. (1983). Natural and man-made noise in the Earth-ionosphere cavity at extremely low frequencies (Schumann resonances and man-made 'interference'), Space Sci. Rev., 35, 83-89.

Rakov, V.A., and M.A. Uman (2003). Lightning: Physics and Effects, Cambridge University Press, $687 \mathrm{p}$.

Rishbeth, H. and O.K. Garriott (1969). Introduction to ionospheric physics, Academic Press, New York and London, $331 \mathrm{pp}$.

Roble, R.G., and P.B. Hays (1979). A quasi-static model of global atmospheric electricity, 2. Electrical coupling between the upper and lower atmosphere, J. Geophys. Res., 84, 7247-7256.

Roble, R.G., and I. Tzur (1986). The global atmospheric-electrical circuit, In: E.P. Krider and R.G. Roble (eds.), The Earth's electrical environment, National Academy Press, Washington, D.C., 206-231.

Roldugin, V.C., Y.P. Maltsev, A.N. Vasiljev, A.Y. Schokotov and G.G. Belyajev (2004). Schumann resonance frequency increase during solar X-ray bursts, J. Geophys. Res. 109, A01216; doi:10.1029/2003JA010019.

Rycroft, M.J. (1965). Resonances of the Earth-ionosphere cavity observed at Cambridge, England, J. Res. NBS, 69D, 1071-1081.

Rycroft, M.J., S. Israelsson and C. Price (2000). The global atmospheric electric circuit, solar activity and climate change, J. Atmos. Sol.-Terr. Phys., 62, 15631576.

Rycroft, M.J., A. Odzimek, N.F. Arnold, M. Fullekrug, A. Kulak and T. Neubert (2007). New model simulations of the global atmospheric electric circuit driven by thunderstorms and electrified shower clouds: The roles of lightning and sprites, J. Atmos. Sol.-Terr. Phys., 69, 2485-2509.

Rycroft, M.J., R.G. Harrison, K.A Nicoll and E.A. Mareev (2008). An overview of Earth's global electric circuit and atmospheric conductivity, In: F. Leblanc et al. (eds.), Planetary Atmospheric Electricity, Springer, 83-105; doi:10.1007/978-0-387-87664-1_6.
Rycroft, M.J., and A. Odzimek (2010). Effects of lightning and sprites on the ionospheric potential, and threshold effects on sprite initiation, obtained using an analog model of the global atmospheric electric circuit, J. Geophys. Res., 115, A00E37; doi:10.1029/ 2009JA014758.

Rycroft, M.J., and R.G. Harrison (2012). Electromagnetic atmosphere-plasma coupling: the global atmospheric electric circuit, Space Sci. Rev., 168, 363-384; doi:10.1007/s11214-011-9830-8.

Rycroft, M.J., K.A. Nicoll, K.L. Aplin and R.G. Harrison (2012). Recent advances in global electric circuit coupling between the space environment and the troposphere, J. Atmos. Sol.-Terr. Phys., 90-91, 198211; doi:10.1016/j.jastp.2012.03.015.

Sao, K., M. Yamashita, S. Tanahashi, H. Jindoh and K. Ohta (1973). Experimental investigations of Schumann resonance frequencies, J. Atmos. Terr. Phys., 35, 2047-2053; .

Sapkota, B.K., and N.C. Varshneya (1990). On the global atmospheric electric circuit, J. Atmos. Terr. Phys., 52, 1-22.

Sato, M., and H. Fukunishi (2003). Global sprite occurrence locations and rates derived from triangulation of transient Schumann resonance events, Geophys. Res. Lett. 30, 1859-1863; doi:10.1029/2003GL017291.

Sátori, G., M. Rycroft, P. Bencze, F. Märcz, J. Bór, V. Barta, T. Nagy and K. Kovács (2013). An overview of thunderstorm-related research on the atmospheric electric field, Schumann resonances, sprites, and the ionosphere at Sopron, Hungary, Surv. Geophys., 34, 1-38.

Schekotov, A.Yu., A.P. Nickolaenko, M. Hayakawa, Y. Hobara, G. Sátori, J. Bor and M. Neska (2013). Worldwide detection of ELF transient associated with the gamma flare of December 27, 2004, Telecomm. Radio Eng+, 72, 1695-1718; doi:10.1615/ TelecomRadEng.v72.118.60.

Schlegel, K., and M. Fullekrug (2002). A D-region conductivity model from EISCAT VHF measurements, Annales Geophysicae, 20, 1439-1445; doi:10.5194/ angeo-20-1439-2002.

Schumann, W. (1952). Uber die strahlungslosen Eigenschwingungen einer leitenden Kugel, die von einer Luftschicht und einer Ionospharenhulle umgeben ist, Z. Naturforsch., 7a, 149-154.

Sentman, D.D. (1990). Approximate Schumann resonance parameters for a two scale-height ionosphere, J. Atmos. Terr. Phys., 52, 35-46.

Sentman, D.D. (1995). Schumann Resonances, In: H. Volland (ed.), Handbook of Atmospheric Electrodynamics, vol. 1, Atmospheric electricity, CRC Press Inc., Boca Raton, Florida, 267-298. 
Sentman, D.D (1996). Schumann resonance spectra in a two-scale-height Earth-ionosphere cavity, J. Geophys. Res., 101, 9479-9487.

Simoes, F.A., R.F. Pfaff and H.T. Freudenreich (2011). Satellite observations of Schumann resonances in the Earth's ionosphere, Geophys. Res. Lett., 38, L22101; doi:10.1029/2011GL049668.

Simpson, J.J., and A. Taflove (2002). Two-dimensional FDTD model of antipodal ELF propagation and Schumann resonance of the Earth, IEEE Antenn. Wirel. Pr., 1, 53-56.

Simpson, J.J. (2009), Current and future applications of 3-D global Earth-ionosphere models based on the full-vector Maxwell's equations FDTD method, Surv. Geophys., 30, 105-130; doi:10.1007/s10712-009-9063-5.

Soriano, A., E.A. Navarro, D.L. Paul, J.A. Portí, J.A. Morente and I.J. Craddock (2005). Finite Difference Time Domain simulation of the Earth-ionosphere resonant cavity: Schumann resonances, IEEE Antenn. Wirel. Pr., 53, 1535-1541.

Swider, W. (1988). Ionic mobility, mean mass, and conductivity in the middle atmosphere from near ground level to $70 \mathrm{~km}$, Radio Sci., 23, 389-399.

Tanaka, Y.T., M. Hayakawa, Y. Hobara, A.P. Nickolaenko, K. Yamashita, M. Sato, Y. Takahashi, T. Terasawa and T. Takahashi (2011). Detection of transient ELF emission caused by the extremely intense cosmic gamma-ray flare of 27 December 2004, Geophys. Res. Lett., 38, L08805; doi:10.1029/2011GL047008.

Tikhonov, V.I (1982). Statistical Radio Technique, second edition, Radio and Communications, Moscow, ch. 2.7 (in Russian).

Tinsley, B.A., and L. Zhou (2006). Initial results of a global circuit model with variable stratospheric and tropospheric aerosols, J. Geophys. Res., 111, D16205; doi:10.1029/2005JD006988.

Tinsley, B.A. (2008). The global atmospheric electric circuit and its effects on cloud microphysics, Rep. Prog. Phys., 71; doi:10.1088/0034-4885/71/6/066801.

Tran, A., and C. Polk (1979a). Schumann resonances and electrical conductivity of the atmosphere and lower ionosphere - I. Effects of conductivity at various altitudes on resonance frequencies and attenuation, J. Atmos. Terr. Phys., 41, 1241-1248.

Tran, A., and C. Polk (1979b). Schumann resonances and electrical conductivity of the atmosphere and lower ionosphere - II. Evaluation of conductivity profiles from experimental Schumann resonance data, J. Atmos. Terr. Phys., 41, 1249-1261.

Velikhov, E.P., ed. (2014). Interaction of electromagnetic fields of ELF controlled sources with the ionosphere and Earth's crust, In: Proceedings of the All-Russian (with the International Participation)
Research and Practice Workshop, Russian Academy of Sciences, Department of Earth Sciences, Geological Institute Kola Science Centre, vol. 1, 206 p.; ISBN 978-5-902643-23-4.

Wait, J.R. (1962). Electromagnetic Waves in Stratified Media, 1st edition, Pergamon Press, Oxford, 372 p.

Wait, J.R. (1970). Electromagnetic Waves in Stratified Media, 2nd edition, Pergamon Press, Oxford, 608 p.

Widdel, H.U., G. Rose and R. Borchers (1976). Experimental results on the variation of electric conductivity and ion mobility in the mesosphere, J. Atmos. Terr. Phys., 81, 6217-6220.

Williams, E.R. (2003). The global electrical circuit, In: J.R. Holton, J. Pyle and J.A. Curry (eds.), Encyclopedia of Atmospheric Sciences, vol. 2, 724-732.

Williams, E.R., V. Mushtak and A.P. Nickolaenko (2006). Distinguishing ionospheric models using Schumann resonance spectra, J. Geophys. Res., 111, D16107; doi:10.1029/2005JD006944.

Williams, E.R. (2009). The global electric circuit: A review, Atmos. Res., 91, 140-152.

Williams, E., and E. Mareev (2014). Recent progress on the global electrical circuit, Atmos. Res., 135-136, 208-227.

Williams, E.R., Y.-J. Wu, M. Friedrich and R.-E. Hsu (2015). Meteor ablation as origin for the D-region ledge in electrical conductivity, paper AE22A-04, presented at AGU Fall Meeting, San Francisco, December 2015.

Wilson, C.T.R. (1929). Some thundercloud problems, J. Franklin Institute, 208, 1-12.

Yang, H., and V.P. Pasko (2005). Three-dimensional finite difference time domain modeling of the Earthionosphere cavity resonances, Geophys. Res. Lett., 32, L03114; doi:10.1029/2004GL021343.

Yang, H., V.P. Pasko and Y. Yair (2006). Three-dimensional finite difference time domain modeling of the Schumann resonance parameters on Titan, Venus, and Mars, Radio Sci., 41, RS2S03; doi:10.1029/2005 RS003431.

Zhou, H., and X. Qiao (2015). Studies on the variations of the first Schumann resonance frequency during the solar flare on 7 March 2012, J. Geophys. Res., 120, 4600-4612; doi:10.1002 / 2014JD022696.

\footnotetext{
${ }^{\star}$ Corresponding author: Alexander P. Nickolaenko, A.Ya. Usikov Institute for Radio-Physics and Electronics, National Academy of Sciences of the Ukraine, Kharkov, Ukraine; email: sasha@ire.kharkov.ua; sashanickolaenko@gmail.com.

(C) 2016 by the Istituto Nazionale di Geofisica e Vulcanologia. All rights reserved.
} 


\section{Appendix 1.}

Here we show the data describing the hybrid profile.

h, km

-

$\lg (\sigma)$

1.512E-14

2.160E-14

$4.090 \mathrm{E}-14$

6.962E-14

$1.049 \mathrm{E}-13$

$1.482 \mathrm{E}-13$

$2.019 \mathrm{E}-13$

$2.712 \mathrm{E}-13$

3.549E-13

4.651E-13

$5.943 \mathrm{E}-13$

$7.629 \mathrm{E}-13$

$9.578 \mathrm{E}-13$

$1.209 \mathrm{E}-12$

1.499E-12

1.867E-12

2.285E-12

2.796E-12

$3.375 \mathrm{E}-12$

4.093E-12

4.891E-12

5.864E-12

$6.930 \mathrm{E}-12$

8.227E-12

9.634E-12

$1.135 \mathrm{E}-11$

1.320E-11

$1.545 \mathrm{E}-11$

$1.788 \mathrm{E}-11$

$2.085 \mathrm{E}-11$

2.416E-11

2.774E-11

3.164E-11

3.626E-11

4.207E-11

4.925E-11

5.762E-11

6.821E-11

7.947E-11

9.359E-11

$1.101 \mathrm{E}-10$

$1.3461 \mathrm{E}-10$

1.555E-10

$42 \quad 1.840 \mathrm{E}-10$

$44 \quad 2.097 \mathrm{E}-10$

$45 \quad 2.410 \mathrm{E}-10$

$46 \quad 2.651 \mathrm{E}-10$

$47 \quad 2.855 \mathrm{E}-10$

$48 \quad 2.991 \mathrm{E}-10$

49

3.183E-10

$-12.346$

$-12.240$

$-12.131$

$-12.032$

$-11.931$

$-11.837$

$-11.742$

$-11.654$

$-11.567$

$-11.485$

$-11.401$

$-11.323$

$-11.244$

$-11.172$

$-11.097$

$-11.029$

$-10.957$

$-10.892$

$-10.823$

$-10.760$

$-10.693$

$-10.629$

$-10.569$

$-10.512$

$-10.452$

$-10.388$

$-10.319$

$-10.251$

$-10.178$

$-10.111$

$-10.040$

$-9.970$

$-9.882$

$-9.819$

$-9.746$

$-9.689$

$-9.629$

$-9.587$

$-9.555$

$-9.535$

$-9.508$

$\lg (\sigma)$
-13.820
-13.665
-13.403
-13.172
-12.994
-12.844
-12.709
-12.581
-12.464

h, km

$\sigma(\mathrm{h}), \mathrm{S} / \mathrm{m}$

$\lg (\sigma)$
-9.482

$50 \quad 3.380 \mathrm{E}-10$

$\lg (\sigma)$
-9.482

51

52

$3.514 \mathrm{E}-10$

3.710E-10

$3.998 \mathrm{E}-10$

4.299E-10

5.229E-10

$6.160 \mathrm{E}-10$

8.044E-10

9.929E-10

58

$59 \quad 1.398 \mathrm{E}-9$

$60 \quad 1.803 \mathrm{E}-9$

$61 \quad 2.731 \mathrm{E}-9$

3.659E-9

$5.896 \mathrm{E}-9$

8.133E-9

$1.365 \mathrm{E}-8$

$1.916 \mathrm{E}-8$

3.249E-8

$4.582 \mathrm{E}-8$

$6.887 \mathrm{E}-8$

$9.636 \mathrm{E}-8$

$1.419 \mathrm{E}-7$

$1.893 \mathrm{E}-7$

2.839E-7

4.258E-7

5.678E-7

7.570E-7

9.463E-7

$1.183 \mathrm{E}-6$

$1.467 \mathrm{E}-6$

1.751E- 6

$2.176 \mathrm{E}-6$

2.602E-6

$3.265 \mathrm{E}-6$

3.927E-6

$5.157 \mathrm{E}-6$

$6.388 \mathrm{E}-6$

$8.895 \mathrm{E}-6$

$1.145 \mathrm{E}-5$

$1.713 \mathrm{E}-5$

$2.285 \mathrm{E}-5$

3.686E-5

$5.091 \mathrm{E}-5$

9.042E-5

$1.230 \mathrm{E}-4$

2.652E-4

4.005E-4

9.690E-4

$1.538 \mathrm{E}-3$

$2.338 \mathrm{E}-3$

$-9.465$

-9.44
-9.409

$-9.377$

$-9.292$

$-9.221$

$-9.105$

-9.013
-8.864

$-8.754$

$-8.573$

$-8.446$

$-8.239$

$-8.099$

$-7.874$

$-7.726$

$-7.497$

$-7.347$

$-7.024$

$-6.848$

$-6.723$

$-6.547$

$-6.371$

$-6.246$

$-6.121$

$-6.024$

$-5.927$

$-5.834$

$-5.757$

$-5.662$

$-5.585$

-5.486
-5.406

-5.406
-5.288

-5.288
-5.195

$-5.051$

$-4.941$

$-4.766$

-4.641
-4.433
-4.293

Table 1. 